\title{
A PARATOPIA, O NIILISMO E A METAFICÇÃO EM DISCURSOS LITERÁRIOS DA OBRA GASTARIA TUDO COM PIZZA, DE PEDRO DUARTE
}

Ricardo CELESTINO

\section{Introdução}

Neste capítulo temos como tema de pesquisa relacionar a paratopia, o niilismo e a metaficção como condições de literariedade para os discursos literários presentes na obra Gastaria tudo com pizza, de Pedro Duarte. Pertencente à terceira onda da literatura de ficção científica brasileira, identificamos na obra que, pela interação entre três agentes essenciais do ato de comunicação literária, quer seja, o autor, o leitor e a instituição literária, ampliamos os efeitos de sentido possíveis para compreender os lugares e as comunidades paratópicas que influenciam na constituição dos discursos literários da ficção científica brasileira. 
A literatura de ficção científica brasileira vive atualmente um momento paradoxal de grande especulação da crítica, do mercado editorial e de eventos multimídias de notoriedade, compartilhando espaço com o cinema e os quadrinhos. Embora no senso comum haja maior exaltação do gênero na perspectiva anglófona, destaca-se, no Brasil, uma cena literária em acontecimento, com comunidades e lugares delineados de forma paratópica, fomentando a constituição de pelo menos cinco décadas de discursos literários pertencentes ao gênero.

Selecionamos como amostra de pesquisa os discursos da obra Gastaria tudo com pizza, de Pedro Duarte, uma vez que nos parece representar um ponto de convergência de boa parte das condições paratópicas que consolidam os discursos literários da ficção científica brasileira. A autoria, a relação entre enunciador e coenuncidor, a institucionalização literária, quando refletidos nos discursos selecionados, também podem contribuir para um olhar mais amplo da cena literária como um todo.

Dessa maneira, utilizamos como direcionamento teórico-metodológico a categoria de paratopia, proposta por Maingueneau (2006). Selecionamos também as reflexões de Nietzsche (1999) acerca do niilismo, posto que tomamos como formação discursiva presente em nossa amostra de pesquisa, essencial para a constituição da força-motriz de literariedade da ficção científica na obra selecionada. E, por fim, destacamos a metaficção, proposta por Hutcheon (1984), como uma das condições estéticas fundamentais para os discursos da ficção científica brasileira, posto que consideramos um gênero da literatura pertencente aos discursos pós-modernistas delineados pela autora.

Organizamos o capítulo em três partes: em Olugar da Literatura de Ficção Científica Brasileira, analisamos a condição paratópica 
da institucionalização dos discursos pertencentes ao gênero nas últimas décadas do século XXI; em A representação de um lugar e um espaço de dizer na enunciação da FCB, examinamos as práticas enunciativas de nossa amostra selecionada, sob a definição de um quadro hermenêutico constituído pelas formações discursivas da FCB, da Filosofia e da Metaficção; e, por fim, em Os lugares e as comunidades paratópicas dos discursos da FCB, voltamos a refletir sobre como os discursos pertencentes ao gênero FCB negociam o pertencimento a um lugar e uma comunidade instituídos de forma paratópica, aprofundando, dessa maneira, as formações discursivas da FCB.

\section{O lugar da Literatura de Ficção Científica Brasileira}

$\mathrm{O}$ ato de comunicação literária implica, para Maingueneau (2006), a correlação de três agentes essenciais: o autor, o leitor e a instituição literária. Produzir enunciados literários exige, por parte do autor, uma ação enunciativa como escritor legítimo, a partir de uma relação com as representações e os comportamentos de certos grupos que, em determinadas épocas, instituem o pertencimento a uma vida literária. No entanto, o gesto que legitima o produtor de um texto como o literário implica em uma metáfora da fuga para o deserto: o campo literário não possui um verdadeiro lugar instituído na sociedade, o qual o autor possa recorrer, entrar com recursos, reivindicar credibilidade, como acontece em discursos científicos, políticos, jurídicos ou de outras esferas sociais, mas trata-se de uma institucionalização negociada na interação entre enunciador e co-enunciador. A contenda acerca do lugar de instituição da comunicação literária implica a consideração de que a produção de uma obra remete a um setor limitado de uma 
sociedade. Nesse sentido, não há propriamente um lugar físico ou jurídico que tem poder sobre os discursos literários, mas podemos identificar uma intersecção de três planos que servem de guia para um analista ou crítico literário examinar o lugar de irradiação das obras literárias: a rede de aparelhos, os posicionamentos e o arquivo.

A rede de aparelhos pressupõe, para Maingueneau (2006), um espaço em que os indivíduos se constituem em escritores ou públicos. Neste ambiente, são garantidos e estabilizados os contratos genéricos considerados literários, pela influência de mediadores, intérpretes, cânones, dentre outros. As redes possibilitam vislumbrarmos um sistema que integra as diversas instâncias que fazem funcionar um determinado cenário literário. Concentram um conjunto de práticas e discursos e garante uma certa reprodução das relações sociais inerentes a uma esfera literária específica.

No caso da Literatura de Ficção Científica Brasileira (FCB), destacamos as ações de editoras e autores independentes como agentes ativos de uma rede de aparelhos que garantem a reprodução das relações sociais do gênero. Causo (2019) destaca a ação de editoras que contam com o trabalho de relançamento de clássicos sob um projeto de book design refinado, como é o caso da Editora Aleph, uma das causas para tornar, nas últimas décadas, a ficção científica um gênero da Literatura em relevância no mercado editorial, dividindo o filão com a Fantasia e o Horror. Grupos editoriais como a Suma, a DarkSide, a Morro Branco e a Companhia das Letras também têm perseguido a mesma estratégia de mercado da editora supramencionada, recuperando obras clássicas, na maioria das vezes da ficção científica anglófona, lançando-as no mercado em edições de luxo. Em paralelo à iniciativa do resgate de obras clássicas, também há ações de publicação de obras contemporâ- 
neas da ficção científica anglófona.

Outra ação destacada por Causo (2019), e que também auxilia na recepção da ficção científica como gênero, é a editoração de obras de não ficção e a presença cada vez maior de revistas acadêmicas especializadas no gênero que ampliam o relacionamento do leitor e seus autores. A Editora Seoman, por exemplo, reúne em seu catálogo biografias de autores de destaque do cenário norte-americano, assim como obras que refletem a historiografia da ficção científica, privilegiando o cenário anglófono. Ainda, há ação de revistas acadêmicas de relevância na crítica literária, das quais destacamos a revista Abusões, organizada pelo Programa de estudos de pós-graduação em Literatura e Crítica Literária da UERJ, que em edição de 2020, realiza um dossiê contemplando o boom da FCB nas últimas décadas.

Por outro lado, é notório que tais ações sejam produtivas para a ficção científica, mas coloque a FCB em um lugar paradoxal, no que diz respeito à recepção de suas obras no mercado literário. As ações editoriais de maior escala privilegiam, salvo algumas exceções, clássicos e contemporâneos estrangeiros, deixando para as ações editoriais de grupos menores e muitas vezes independentes, a editoração e a circulação de trabalhos nacionais. Obras de autores da primeira e segunda ondas da FCB, por exemplo, são cada vez mais raras no catálogo de grandes editoras, ou em evidência nas estantes físicas e virtuais das grandes livrarias. Leitores vorazes de ficção científica muito provavelmente cansaram de ouvir falar de autores como Philip K. Dick, H.G. Weels, William Gibson, mas podem contar com um conhecimento tímido sobre as obras de $A n$ dré Carneiro, Roberto de Sousa Causo, Luiz Brás, dentre tantos que constituem o legado tradicional da FCB. 
Dessa maneira, a FCB fica restrita a ações editoriais mais tímidas de grupos editoriais como a Patuá, a Monomito, a Lendari, dentre outras editoras de pequeno e de médio porte, quando comparadas à Companhia das Letras, por exemplo. Há, nesse sentido, uma impressão primeira de que autores nacionais da FCB ou não existem, ou são versões adaptadas de autores estrangeiros da ficção científica, o que reproduz um comportamento de manada para a disseminação de preconceitos entorno das obras nacionais. Esse cenário só terá mudança a partir de ações editoriais revolucionárias e o grupo editorial Pipoca \& Nanquim, em destaque no mercado de quadrinhos, pode ser uma alternativa tímida para alterar a recepção da FCB por parte de uma comunidade de leitores. Contando com um canal de YouTube de 210 mil inscritos, lançou em 2019 pelo menos dois títulos que se enquadram no fantasismo brasileiro: Gastaria tudo com pizza, de Pedro Duarte, e A floresta das árvores retorcidas, de Alexandre Callari.

Outro fator essencial para conhecermos o lugar de instituição dos discursos da FCB são os posicionamentos. O campo literário implica um lugar de confrontos estéticos que investem o comportamento dos gêneros de discurso. Diferentes posicionamentos se acham em relação de concorrência em sentido amplo, delimitando-se mutuamente. Dessa maneira, para Maingueneau (2006), o campo pode assumir valor discursivo, adotando uma dinâmica em equilíbrio instável. Jamais será homogêneo, posto que em um mesmo campo haverá posicionamentos dominantes e dominados, centrais e periféricos.

Na FCB, Matangrano \& Tavares (2018) destacam que uma das condições para o estabelecimento do insólito em seus discursos é o fantasismo. Compreendendo-o como um termo guarda-chuva que engloba múltiplas expressões estéticas, o fantasismo converge gêneros distintos sob uma dinâmica em comum. Tomando-o por 
posicionamento central da FCB das últimas décadas, o fantasismo engloba obras dedicadas à literatura infantil, ao folclore nativoamericano, ao imaginário de matriz africana e à ficção científica, concentrando as condições de um movimento literário do século XXI que ganha o mercado editorial e traz visibilidade à literatura fantástica brasileira.

A noção de movimento fantasista em destaque por Matangrano \& Tavares (2018) engloba a FCB como uma das subcategorias em produção. Utilizado na comunidade de leitores, autores e editoras do gênero, o movimento fantasista designa autores de fantasia. É importante destacar que o conceito de fantasia, no século XXI, é tomado por um alargamento que define obras insólitas e que há, assim, um continuum que pode distanciar e aproximar uma obra de fantasia de uma obra de ficção científica. Deparamos com essa dificuldade de categorização nas prateleiras das livrarias, em serviços de streaming de filmes e séries e principalmente na classificação de jogos de video-game.

Fantasia e ficção científica são, para Matangrano \& Tavares (2018), termos guarda-chuva que acolhem inúmeras subcategorias e modos narrativos como o Dark Fantasy, a fantasia urbana, a fantasia histórica, a fantasia utópica e distópica, o steampunk, o solarpunk, dentre outros. Trata-se também de uma imposição mercadológica que acaba encontrando na própria crítica literária acadêmica vazão para determinar regularidades de uma subcategoria e outra, assim como suas zonas de confluências.

No entanto, por que tratarmos o fantasismo por movimento? Matangrano \& Tavares (2018) observam que desde a década de 1960, autores, leitores e editores de fantasia e ficção científica vêm consolidando a cultura de agremiações, prêmios e revistas especializadas que levantam uma bandeira em comum em torno dos 
ideais estéticos da fantasia e da ficção científica desenvolvidas no Brasil. Tais ações têm, nas últimas décadas, unificado editores, autores e leitores e podemos contar com:

- publicações de títulos que alcançam notoriedade, como o caso de Max Mallmann na década de 2000 ter sido indicado como finalista do Prêmio Jabuti com Síndrome de Quimera;

- criação de editoras, selos específicos voltados a vertentes e subcategorias específicas como a Editora Malê que se dedica na publicação de obras do afrofuturismo e a $A V E C$ com coleções extensas do steampunk e da história alternativa;

- aumento de estudos teóricos e a penetração das questões estéticas de subcategorias específicas nos meios universitários brasileiros, como é o caso do lançamento em 2018 de Fantástico Brasileiro: o insólito literário do Romantismo ao Fantasismo, de Bruno Anselmi Matangrano e Eneias Tavares e Fractais Tropicais, uma antologia de contos da FCB da década de 1960 até a década de 2010, organizada por Nelson de Oliveira;

- a criação de eventos, prêmios e reuniões coletivas congregando fãs, escritores, editores e críticos para o debate e a valorização da produção do fantástico nacional, dos quais destacamos a ação de Duda Falcão e Cesar Alcázar que promovem um dos maiores eventos de fantasia e ficção Científica brasileiras, em Porto Alegre: a Odisseia de Literatura Fantástica. 
Matangrano \& Tavares (2018) observam, por fim, que o lugar de irradiação da obra literária implica uma atividade criadora relacionada a uma memória, apreendida pelos conflitos do campo, retrabalhadas constantemente. Trata-se de uma memória interna da literatura que, para além do intertexto, inclui um arcabouço semelhante a acervos em uma biblioteca.

No caso da FCB, identificamos as influências das três ondas que constituem uma breve e recente historiografia do gênero em produção no Brasil e de obras tradicionais traduzidas pelas grandes editoras desde a década de 1960. Oliveira (2018) observa que as três ondas da FCB concentram a consolidação de mundos fictícios que golpeiam o mundo empírico, atacando as restrições socioculturais responsáveis por disseminar desigualdades em um país colonial. Nas obras da FCB encontramos temas que contemplam a luta de classes, a desigualdade de gêneros e de etnias e o existencialismo constantemente denunciados e subvertidos sob a roupagem da utopia e da distopia.

Contudo, Oliveira (2018, p. 09) destaca que:

'(...) a transgressão não para no contrato social. Claro que não. Nas dobras da literatura, o escritor se vinga não apenas das sociedades opressoras, mas também da natureza opressora.

Contrabandista de sonhos lúcidos, esse contraventor não aceita o determinismo biológico da evolução e do código genético, tampouco o determinismo físico da gravidade e da entropia." 
Em linhas gerais, Oliveira (2018) observa que o enunciador da FCB é um escritor-contraventor que subverte leis da natureza e permite que seus personagens atravessem paredes, desenvolvam máquinas do tempo, desafiem a realidade em imersões virtuais, viajem na velocidade da luz. A condição humana, de limites biológicos e sociais tomados por simplórios, é elevada a uma condição transumana pelo subterfúgio da ciência, da tecnologia e da magia: componentes do insólito.

Ao longo de pelo menos cinco décadas de produção da FCB, a contar da primeira onda, a geração GRD, até o atual momento no qual vivenciamos a concomitância de duas gerações de escritores em produção massiva a todo vapor, foi possível identificar a consolidação de alguns subgêneros da FCB. Em sua breve historiografia, Oliveira (2018) lista pelo menos onze variações do gênero identificáveis em obras nacionais ao longo de cinco décadas: o ciberpunk, a ficção esotérica, a ficção exobiológica, a ficção científica hard, a ficção científica soft ou new wave, a ficção de imortalidade, a ficção de inteligências artificiais, o new weird, as ficções de contatos alienígenas, ficções de realidades paralelas ou alternativas, as space operas, as ficções ufológicas, dentre outras.

Para Oliveira (2018, p. 21), a FCB é uma espécie de fractal, pois "seu tronco se ramifica em diferentes direções, gerando magníficos e hipnotizantes galhos literários, mas sem perder a identidade com uma espécie de modelo original". Dessa maneira, os subgêneros se entrelaçam em uma trama literária que, por exaustão nas múltiplas tentativas de classificação, denominamos ficção científica ou ficção fantasista. 


\section{A representação de um lugar e um espaço de dizer na enunciação da FCB}

Maingueneau (2006) observa que, quando se trata da criação literária, a enunciação desestabiliza as representações que se tem de um lugar e de um espaço de dizer. O autor compreende que meios literários são fronteiras e, enquanto existência social, seus discursos se constituem sob a (in)segurança de se fechar em si mesmos, não se confundindo com a sociedade comum e, ao mesmo tempo, estabelecendo laços com a sociedade.

Para examinarmos a enunciação literária da FCB, selecionamos como amostra de pesquisa discursos extraídos da obra Gastaria tudo com pizza, de Pedro Duarte. A narrativa tem como ponto de partida explorar a trajetória de descoberta da capacidade de uma máquina de escrever possibilitar o seu usuário a viajar no espaço-tempo, tendo como protagonista, Bob. Em Pipoca \& Nanquim (2020), é possível identificarmos que o enunciador busca destacar os seguintes aspectos da jornada:

Cansado de sua monótona rotina, Bob - que se chama Bernardo, mas é conhecido como Bob - poderia simplesmente largar o trabalho e, quem sabe, fazer planos para uma viagem longa que incluisse uma ilha paradisíaca. Abandonaria redes sociais, e-mails, compromissos e esqueceria até que relógios existem. Mas ele preferiu colocar a mão na massa e construir um aparato que gera portais que lhe permitem viajar pelo tempo e espaço!

Embora o release não componha propriamente a enunciação literária em Gastaria tudo com pizza, os enunciados apresentados 
servem de ponto de partida para refletirmos sobre aquele que o enunciador tem como foco de subjetividades para o desenvolvimento dos discursos literários: Bob, um sujeito de classe média de uma cidade grande, em uma rotina que não lhe oferece autorrealização, decide construir uma máquina de escrever que viaja no espaço-tempo e testar novas possibilidades de vida em metaversos.

De antemão, identificamos nos discursos literários a força do enunciador em desarticular e dialogar com o real observado e as representações de um novo lugar e um novo espaço de dizer. Em outras palavras, Bob e sua invenção para viajar no espaço-tempo canalizam a subjetividade que representa a fronteira entre existências sociais possíveis e o imaginário por meio do insólito.

Compreendemos que essa dupla representação entre as existências sociais presentes na obra e o insólito implicam ao discurso literário da FCB uma coenunciação metaficcional. Isso significa que há, na cenografia criada, o questionamento do estatuto linguístico e narrativo do processo de produção e recepção de cada rotina criada, a fim de subverter as convenções do gênero literário romance. Diferente de outras obras literárias, a FCB possui a preocupação de, no próprio discurso, explicitar o fazer ficcional e suas regras de execução.

Em outras palavras, os enunciados rompem, de alguma maneira, com a ilusão de realidade da obra ficcional, da qual Faria (2012) observa tratar-se de um tipo de antirromance. A ficção proposta nos discursos da FCB transgride a escrita romanesca no interior da própria obra ficcional, tal qual em Dom Quixote. Nesta obra, presenciamos a reação do enunciador contra romances de cavalaria, contando ao co-enunciador a jornada de um cavaleiro andante de dois mundos: o mundo medieval imaginário e o mundo da burguesia em ascensão no século XVI imaginado pelo enunciador. 
Tal relação também ocorre nos discursos literários da FCB, principalmente o que selecionamos: o enunciador narra a jornada de alguém em um mundo imaginário do insólito sob a sombra nem sempre explícita de um mundo contemporâneo imaginado.

Bob vive em uma realidade familiar com a realidade a qual vivemos no século XXI: o protagonista está cansado das redes sociais, dos e-mails, dos compromissos profissionais e pessoais. Contudo, esta não é a realidade bruta, senão a realidade imaginada pelo enunciador. A invenção que permite Bob viajar no espaço-tempo é o gatilho insólito para uma nova realidade, ou o novum, na perspectiva de Roberts (2018, p. 37):

(...) novum: o dispositivo, o artefato ou premissa ficcionais que põem em foco a diferença entre o mundo que o leitor habita e o mundo ficcional do texto de FC. Esse novum pode ser algo material, como uma espaçonave, uma máquina do tempo ou um dispositivo de comunicação mais rápido que a luz; ou pode ser algo conceitual, como uma nova versão de gênero ou consciência.

O novum, tal como propõe Roberts (2018), é condição da FCB em abrir uma janela a mais nesse mundo imaginado. Contudo, compreendemos que o mundo que o leitor habita, contemplado nos discursos literários, passa pelo filtro do processo ficcional, já que é um mundo possível proposto pelo enunciador. Essa não é uma condição da FCB, mas parece uma condição da Literatura. A FCB propõe um degrau a mais nesse processo de ficcionalização, implicando uma metaficção no sentido que temos o contato com dois ou mais mundos ficcionais. Não temos apenas o mundo possível habitado por Bob, mas o mundo possível somado a um novo mundo onde há possibilidade de se criar máquinas que viajam no 
espaço-tempo e de se experienciar a vida em metaversos, tornando real e aplicável, naquele universo criado pelo enunciador, a teoria das cordas da Mecânica Quântica.

Maingueneau (2006) observa, ainda, que os discursos literários não pertencem a um espaço social definido. $O$ enunciador não é um filósofo ou um psicólogo, mas tem a sensibilidade intelectual de manter-se na fronteira entre a inscrição de áreas como a Filosofia ou a Psicologia e abandoná-las, posto que não tem autoridade em suas fronteiras. Dessa maneira, lugares, grupos, comportamentos contemplados na enunciação são tomados em um pertencimento impossível.

No caso dos discursos da FCB, identificamos que o enunciador destaca potencialidades do mundo comum e familiar ao co-enunciador e submete-as à ordem do fantasismo. Identificamos, na obra de Pedro Duarte, enunciados que desenvolvem a jornada de um protagonista desmotivado psicologicamente, racionalizando sua vida pela ordem filosófica niilista. Tomando o niilismo por formação discursiva presente nos discursos em análise, identificamos em Duarte (2019) enunciados do tipo:

Durante anos - a vida toda, para ser mais exato - estudou física e as realidades quânticas, multiversos, paradoxos dos cientistas com nomes de padaria, tabus da ciência contemporânea e devaneios de filósofos que usavam palavras complicadas com o único propósito de nunca serem entendidos de verdade. Mesmo estagnado como subgerente de uma loja de materiais de construção, Bob nunca tinha deixado de experimentar e inventar. 
Apesar dos conhecimentos avançados em química $e$ também matemática, era um cara normal, que assistia futebol, indicava o melhor cimento para a calçada da sua casa durante o horário comercial e comia porcaria de madrugada. De exótico, só tinha a obsessão com a ideia de ir para outro lugar. Ele não sabia que lugar era esse, mas sempre dizia para si mesmo: a vida não pode ser só isso.

O mundo estava preso a regras imutáveis: dinheiro, o sistema de aposentadoria, lazer, relacionamentos, bola de futebol, sexo, mergulhar pelado no rio, doença, reclamações na internet, cura, lambada, ego, gravidade, tijolo, maquiagem, meditação, desenho animado, frigobar, oxigênio...

O enunciador ficcionaliza Bob com o cuidado de situá-lo a um tipo de sujeito que racionaliza o mundo sob o direcionamento filosófico niilista. Identificamos que Bob sintetiza em sua jornada a ruptura de expectativas com a moral cristã. Em uma realidade na qual não há sanção nem refúgio a um além, resta para Bob, mesmo com todo o conhecimento de física, química e matemática avançadas, assistir a jogos de futebol, indicar cimentos para calçada em horário comercial e comer porcarias de madrugada. A partir de Nietzsche (1999), compreendemos que esse tipo de olhar sob a realidade implica um pensamento monoteísta das coisas do mundo, assumindo que tudo na vida carrega um único sentido, a inexequibilidade dessa única interpretação das coisas, que o sujeito dedica força descomunal, leva Bob a desconfiar de todas as outras leituras possíveis para aquele mundo. A existência naquela realidade passa a agir sobre o sujeito por existência como castigo, como erro. Resta a Bob dedicar forças à construção de 
uma máquina de escrever que lhe permita viajar no espaço-tempo e experienciar outras realidades, posto que aquela em que está já foi esgotada em sua complexidade.

Bob canaliza em sua jornada a perda de questões essenciais para uma sociabilidade progressista como o gosto pelo egoístico, pelo necessário. A consequência é que o estímulo às coisas se esvai e ele encontra-se cansado. Nietzsche (1999) destaca, como traço do niilismo, a queda dos valores cosmológicos, propondo três partes que podemos identificar disseminadas na trajetória de Bob.

Em primeiro lugar, o niilismo atua em Bob como estado psicológico. Na filosofia, Nietzsche (1999) destaca que o niilismo implica a procura por um sentido que não está naquilo que dedicamos forças em buscar. Na jornada de Bob, por sua vez, identificamos a busca por uma sensação de autorrealização que ele não sabe muito bem onde encontrar e deposita esperança que o experimento seja a chave com essa resposta. A consequência disto é a tomada de consciência de um longo desperdício de forças ao longo da jornada. Bob e o homem niilista cercam-se por sensações de insegurança e imaginam que algo deveria ser alcançado, mas todas as buscas os levam a lugar nenhum. Dessa maneira, o nada é alcançado e Bob é, pouco a pouco, ao longo da jornada, acometido pela desilusão sobre uma finalidade do vir-a-ser, não conseguindo formular uma resposta racional para a contenda: qual a razão de vir-a-ser?

O questionamento sem resposta acerca da razão de vir-a-ser leva Bob a um outro estágio do niilismo proposto por Nietzsche (1999): uma forma de monismo, onde coloca-se uma totalidade, uma sistematização, uma organização em todo acontecer e debaixo de todo acontecer. Bob possui, ao longo de sua jornada, um sentimento de conexão e dependência diante de um todo infinitamente superior a ele. Uma espécie de modus divindade, em que Bob 
observa que não há um universal divino, mas na medida em que se avança em novas descobertas, na exploração do espaço-tempo, há um encontro com o que Nietzsche (1999) observa tratar-se de a perda da crença em seu valor essencial. Para o filósofo, com o vir-a-ser nada deve ser alvejado. Isso significa que sob todo o vir-a-ser, não reina nenhuma grande unidade em que o indivíduo pode submergir como elemento de supremo valor. Identificamos esse tipo de impressão de mundo na jornada criada para Bob, uma vez que, por mais que ele explore inúmeras opções de universos no espaço-tempo, ele não encontra uma Verdade reconfortante, mas apenas o reforço na confirmação de que o vir-a-ser é uma ilusão e o mundo para além de todos os mundos possíveis é inalcançável.

Dessa maneira, o enunciador, tal qual um filósofo niilista, demonstra na jornada de Bob que o mundo e todas as possibilidades de metaversos foram montados somente por necessidade psicológica. Encerra-se em Bob a terceira forma de niilismo: a descrença de um mundo metafísico. Para Bob, a realidade do vira-ser é a única possível. $\mathrm{O}$ enunciador proibi-lhe todo acesso a uma divindade que lhe conforte, a ponto de que Bob não suporta o mundo em que está. $\mathrm{O}$ caráter global da existência de Bob não pode ser interpretado nem com o conceito fim, nem com o conceito unidade, nem com o conceito verdade. Com isso, a partir de Nietzsche (1999), podemos compreender que na jornada de Bob nada é alvejado e alcançado, assim como falta uma unidade que abrange a pluralidade do acontecer, mesmo com a possibilidade de explorar metaversos e múltiplas realidades. Cada um dos mundos explorados, em algum momento, perderá seu valor devido às categorias fim, unidade e ser, terem sido retiradas do sujeito-viajante.

Em linhas gerais, identificamos que o enunciador utiliza, nesse sentido, das formações discursivas do niilismo, proposto pela Filosofia desenvolvida por Nietzsche (1999). Contudo, embora 
ele tenha propriedades para desenvolver um cenário complexo que envolva a jornada ficcional de um sujeito sob a ordem de uma vida niilista, o enunciador não tem a autoridade de um filósofo para certificar a jornada contada. Isso significa que os discursos da FCB pertencem a um lugar de reflexão profunda de questões culturais e sociais da vida moderna, ao mesmo tempo que possui comportamento parasitário, posto que o enunciado literário utiliza dos discursos constituintes, em nosso caso da Filosofia, para inaugurar um lugar (im)possível de existir na vida social e no mundo familiar do co-enunciador. Nesse sentido, Bob é tão possível quanto impossível em nossa realidade.

\section{Os lugares e as comunidades paratópicas dos discursos da FCB}

O discurso literário emerge de forma local, constituindo-se mediante normas e relações de forças dos lugares em que surge. Maingueneau (2006) compreende que as relações entre escritor e sociedade, escritor e obra, obra e sociedade submetem os discursos literários a um território definido.

Em discursos da FCB, identificamos que a divisão das tendências da FCB em ondas possibilita examinarmos os lugares e as comunidades que consolidam um comportamento paratópico para tais produções. Gastaria tudo com pizza é uma obra que podemos inserir na terceira onda da FCB. Isso significa que encontramos enunciados com desempenho estético de mundos insólitos, tal qual observam Matangrano \& Tavares (2018, p. 131):

No século XXI, (...), o elemento mais característico da nova literatura fantástica é a criação de mundos em suas 
mais diversas potencialidades, não raro ocorrendo um hibridismo entre dois ou mais modos narrativos, com supremacia, no entanto, da fantasia. Nesse sentido, duas vertentes floresceram mais do que outras, difundindo-se e se multiplicando em outras variantes. É o caso da ficção científica, em constante expansão desde a década de quarenta do século anterior (...) e sobretudo, na fantasia.

Matangrano \& Tavares (2018) destacam, em linhas gerais, que uma das características marcantes dos discursos da FCB na terceira onda é a intersecção entre a especulação científica e a fantasia. O continuum que implica mais ou menos científico ou mais ou menos fantasista parece definir a FCB do século XXI, no intuito de não priorizar a predição de um futuro utópico ou distópico, mas representar questões tópicas do presente em mundos criados que encontram no insólito uma dupla possibilidade criativa: a fantasia e a especulação científica. Tal condição possibilita que os discursos extraídos da obra Gastaria tudo com pizza integrem-se neste lugar paratópico de terceira onda da FCB, como podemos examinar nos enunciados abaixo, em Duarte (2019, p. 150):

(...) não é possível prever todas as anomalias que podem acontecer em todos os possíveis tempos e dimensões, muito menos quando falamos de algo criado e regulamentado anos-luz à frente e que, portanto, já aconteceu há muito tempo, mas ainda não chegou à Terra, ao mundo de Bob ou ao planeta Spalash - os três, vale ressaltar, geograficamente localizados no mesmo lugar (se é que podemos usar esse termo), mas em diferentes dimensões, e todos atrasados diante de boa parte do que já 
aconteceu cosmo afora (embora adiantados em relação a outros lugares).

Nos enunciados em destaque, identificamos o desenvolvimento do insólito sob duas perspectivas: da especulação científica e da fantasia. A especulação científica implica a consideração de que sob a viagem no espaço-tempo conseguimos acessar multiversos, ou versões diferenciadas de realidades no planeta Terra. Considerar em seus discursos a possibilidade de viagem no espaço-tempo é estabelecer um pertencimento a um lugar paratópico de determinados discursos ficcionais que refletem essas possibilidades, dentre eles discursos dos quadrinhos, como Flash, a Liga da Justiça, X-men, da Literatura de Ficção Científica Anglófona, como Viagem ao centro da Terra, Planeta dos Macacos, e, por fim, dos filmes, como Perdido em Marte, De volta para o futuro, dentre outros.

Ainda, a consideração de multiversos projeta os discursos literários a um lugar paratópico de discursos metaficcionais, desenvolvidos comumente na Literatura Pós-moderna, posto que como observado por Hutcheon (1984), são narrativas que provocam no co-enunciador a construção dos efeitos de sentido por meio de processos de espelhamento de realidades possíveis e a autorreferência. Quando o co-enunciador se depara com uma realidade criada que faz referências a seu mundo, como por exemplo o planeta Spalash e o sistema totalitário que vivem seus habitantes, o discurso provoca relação de três realidades síncronas: a realidade ficcional de Bob, versão da realidade do co-enunciador; a realidade do co-enunciador sob autorreferência à realidade de Bob; uma nova realidade do planeta Spalash, de habitantes submetidos a um sistema totalitário de um líder absolutista, o qual o co-enunciador pode estabelecer relação a sistemas de poder ditatoriais ou até mesmo à organização social da Idade Média. 
O co-enunciador, nesse sentido, necessita assumir a postura de um leitor coautor para adentrar ao espaço literário evocado pelos discursos ficcionais e estabelecer os links necessários para refletir sobre as regras de todas as camadas de mundos e universos propostos. $\mathrm{O}$ enunciador, por sua vez, assume uma postura comum dos autores de obras metaficcionais de Literaturas pós-modernas, subvertendo as noções de objetividade, posto que estamos diante de um mundo onde é possível viajar no espaço-tempo e conversar com alienígenas, e naturalidade, uma vez que o alcance das tecnologias criadas por Bob estão a serviço das regras criadas pelo enunciador e não pelas limitações da natureza da espécie humana. Bob é um novo tipo de ser humano, um sujeito paratópico que está e não está entre os homens comuns e possíveis no mundo real. $\mathrm{O}$ que faz dele ser paratópico são suas genialidades insólitas, as habilidades que proporcionam viagem no espaço-tempo e contato com alienígenas. Nesse sentido, temos o que Hutcheon (1984) define como um discurso metaficcional: a ficção sobreposta à ficção.

Outra relação de especulação científica que possibilita o discurso em destaque pertencer à FCB é a sua relação paratópica com a Física teórica. Obras de Ficção Científica, seja nos quadrinhos, no cinema, nos video-games ou na literatura que refletem sobre o espaço-tempo estabelecem, umas mais outras menos, relações com as formações discursivas da Física. Em Nerdologia (2020), identificamos que a Física é baseada em constantes fundamentais como a velocidade da luz, a carga de um elétron ou a constante gravitacional universal. A relação entre elas sugere os valores para a possibilidade de nossa existência. Uma das questões ainda no campo teórico da Física é: como essas constantes são tão afinadas a ponto de gerar a vida? Uma das respostas possíveis, ainda no campo teórico, é de que não vivemos em um universo, mas em um universo de infinitos universos com diferentes constantes e diferentes propriedades físicas. Nos discursos da FCB, a teoria é 
posta em prática, sob o aparato da especulação e da realização de uma condição insólita ao mundo tópico, estabelecendo lugar com a fantasia. Isso significa que, de forma paratópica, os discursos da FCB transitam pelo lugar instituído da Física, amplificando uma teoria ainda não comprovada, mas ao mesmo tempo não pertencem a este lugar, posto que a condição dada para viagem no espaço-tempo é potencializada pelo aparato da fantasia, com espécies alienígenas, mundos com outras regras e a presença de uma espécie de magia entorno dos habitantes do planeta Spalash.

Maingueneau (2006) observa, ainda, que os discursos literários dizem sobre coisas do mundo, colocando em jogo, na enunciação, a impossível inscrição social dessa mesma enunciação. Tal inscrição social, se sofre as consequências de não encontrar um lugar institucional que a legitime, sedimenta-se na vida literária individual, estruturada por academias, círculos, coletivos, escolas, grupos que se distribuem pelo campo literário sob distintas reivindicações estéticas. O escritor, nesse sentido, se situa em uma espécie de tribo escolhida que ele inclui em seu panteão pessoal e cujo modo de vida e cujas obras lhe permitem legitimar sua própria enunciação.

Nos discursos da FCB, identificamos que a vida literária de cada autor pode influenciar na construção dos efeitos de sentido dos enunciados desenvolvidos. A atuação do autor em coletivos e grupos de estudo, sua atividade em redes sociais, a produção de enunciados que sustentam e refletem um olhar que potencialize os enunciados desenvolvidos nos discursos da FCB, além de fidelizar leitores do fandom, passa a ser um direcionamento para a coenunciação. Mistura-se, nesse sentido, atuações publicitárias entorno da obra, com direcionamentos críticos que podem auxiliar o co-enunciador na adesão de um determinado quadro hermenêutico para a construção dos efeitos de sentido nos discursos desenvolvidos. 
Em Gastaria tudo com pizza, identificamos que o público-alvo de leitores da obra são seguidores do canal Pipoca \& Nanquim, especializado em traduzir, editar e distribuir obras de histórias em quadrinhos inéditas, de autores reconhecidos no fandom, para o Brasil. A obra de Pedro Duarte introduziu um selo de editoração e publicação de obras literárias nacionais dentro do grupo editorial Pipoca \& Nanquim, que conta hoje com 210 mil inscritos, revelando a irradiação de um fandom significativo para a obra. Como evento promocional da obra de Pedro Duarte, os editores do canal convidaram o autor para um bate-papo. A conversa com a extensão de quarenta minutos apresenta enunciados de referência aos discursos desenvolvidos em Gastaria tudo com pizza, estabelecendo diretrizes que podem nortear a coenunciação dos discursos, definindo um quadro hermenêutico, como podemos observar em Pipoca \& Nanquim (2020):

(...) é uma fiç̧ão científica no melhor estilo Doulgas Adams, no melhor estilo Ricky and Morty. (...)

(...) em que momento o livro tornou-se um sci-fi muito no tempo contemporâneo? Por que acho que um dos grandes méritos do livro é ser um reflexo dessa geração. Ele é muito importante, ele representa um zeitgeist do brasileiro em 2018 e 2019: a relação com a internet, a relação que temos em não se encontrar. Eu estou nessa profissão, é legal, só que não se encontra... isso é muito dos dias de hoje. Quando virou este o questionamento do livro? (...)

Na entrevista, Pedro Duarte apresenta-se como o enunciador-autor por detrás das cortinas, nos bastidores, revelando seu 
processo de criação e expondo os direcionamentos hermenêuticos que compõem os discursos desenvolvidos em Gastaria Tudo com Pizza. O enunciador coloca-se no lugar de quem desenvolve discursos da FCB em terceira onda, estabelecendo relações com formações discursivas do niilismo e da Ficção Científica anglófona disseminada em best-sellers canônicos, como é o caso de Douglas Adams, e desenhos animados, como o Ricky and Morty. Embora a construção dos efeitos de sentido tenha como primazia os enunciados literários presentes na obra, enunciados de outros discursos que estabelecem relação de irradiação da obra a um determinado público-leitor, influencia no processo de coenunciação dos discursos literários. Isso significa que a obra não está isolada no mundo, disponível ao leitor dentro de uma garrafa, encontrada em mar aberto. A obra literária estabelece relações com comunidades de booktubers, críticos, coletivos literários que contribuem para delimitar quadros hermenêuticos que podem confirmar ou não no processo de construção de sentidos ao longo da enunciação. No caso da obra Gastaria tudo com pizza, o ponto de partida dos discursos que comentam sobre os discursos literários é pontuar que a obra estabelece diálogo com a narrativa desenvolvida por Douglas Adams em Guia do mochileiro das galáxias e a série animada Ricky and Morty. Tanto um quanto outro são postos como uma referência para o fandom da ficção científica no Brasil e no mundo, concentrando narrativas que misturam especulação científica, humor e um niilismo autodestrutivo. Dessa maneira, os discursos desenvolvidos em Gastaria tudo com pizza podem estar submetidos às irradiações de um quadro hermenêutico delimitado previamente, por discursos que comentam sobre a obra e trabalham um marketing em paralelo com um olhar crítico.

Tal condição não é uma particularidade da obra de Pedro Duarte. Cada vez mais, nas redes sociais e nos canais de distribuição de vídeos como YouTube, identificamos influenciadores digitais 
especializados em obras literárias do insólito. Os booktubers realizam, muitas vezes, o trabalho do crítico literário que produz uma resenha a um jornal de grande circulação. Uns mais, outros menos, possuem condições de definir ao co-enunciador um direcionamento dos discursos da FCB, inserindo-os em determinados lugares ou comunidades que possuem comportamento paratópico, posto que como observamos no início deste capítulo, não contam com a burocracia das instituições, mas com uma validade flutuante, muitas vezes marginal, que depende muito mais do desempenho do enunciador, do que de uma confirmação de um crítico ou de um booktuber. Contudo, mesmo dependendo mais dos esforços do enunciador, do que da comunidade que diz o que aqueles discursos são e onde eles se situam, há um regime de compensação, onde um não deixa de influenciar o outro, na coenunciação dos discursos da FCB.

Maingueneau (2020) também observa que certos discursos contam com agenciamentos estéticos para potencializar a construção dos efeitos de sentido dos enunciados textuais. Destaca que não são apenas coisas mudas que estão na obra, mas servem como parceiros da comunicação e, nesse sentido, como analistas deveríamos dar mais relevância a esses objetos. Em discursos literários, os agenciamentos estéticos contribuem como algo a mais para incluir a obra em uma determinada comunidade literária e estabelecer a ponte entre autor e leitor.

Nos discursos da FCB, os agenciamentos estéticos da capa e muitas vezes do design gráfico que compõem a diagramação e a escolha de letras em uma obra contribuem para localizar os enunciados literários em comunidades literárias fomentadas pelo fandom. Determinados tipos de capas, por exemplo, podem servir como ponto de partida para considerar os discursos da FCB pertencentes a um certo tipo de subgênero como o steampunk, o cyberpunk, 
a spaceopera, dentre outros. Certos tipos de escolhas de letras ou diagramações podem remeter a discursos literários que estabeleçam relações com as narrativas pulp norte-americanas das décadas de 1930 a 1950, muito fomentadas pelas comunidades literárias da FCB. O agenciamento da capa e de outros recursos semióticos estabelecem relação com os enunciados literários e contribuem para a construção dos efeitos de sentido dos discursos da FCB.

Em Gastaria tudo com pizza, por exemplo, identificamos que o projeto gráfico e a capa, desenvolvidos pela designer Giovanna Cianelli, potencializam as possibilidades de efeitos de sentido dos enunciados literários. A artista, em entrevista ao site No olhar do satélite, observa que seu trabalho teve inspiração em trabalhos visuais de autores renomados do fantasismo, como Jack Kirby, primeiro desenhista de heróis clássicos da Marvel Comics, dentre eles Spider Man e X-men, e da cultura pop, como Terry Giliam, de Monty Python. Embora esta seja uma impressão dada pela artista em uma entrevista concedida e ela não tenha controle total dos efeitos de sentido que um co-enunciador detém de um discurso literário, como analista não podemos desprezar que mais duas formações discursivas somam-se na constituição de um direcionamento hermenêutico para a coenunciação dos discursos literários em Gastaria tudo com pizza: as formações discursivas das narrativas heroicas da era de ouro dos quadrinhos, especificamente dos tempos de parceira de Stan Lee e Jack Kirby; e o humor crítico, politizado, muitas vezes niilista e autodestrutivo de Terry Giliam, na série televisa e na série de filmes do grupo britânico Monty Python.

\section{Conclusão}

Investigar o lugar institucional dos discursos literários se faz produtivo, uma vez que trata-se de discursos que negociam seu 
pertencimento a um lugar na prática enunciativo-discursiva. Ainda, podemos identificar ao longo da pesquisa que a noção de lugar e comunidade, quando tratamos de discursos literários, são de apreensões líquidas, uma vez que há muitos influenciadores para essa constituição. No caso da FCB, por exemplo, não há um lugar físico que legitime os discursos literários, mas uma rede de ações que, quando associadas, constitui de forma instável caminhos possíveis para uma institucionalização de uma cena literária fantasista.

Contudo, compreendemos que é na criação literária e especificamente na enunciação que as representações de um espaço e de um lugar de dizer são observados. Eventos, ações editoriais, palestras de autores com seus leitores constituem arcabouços importantes para consolidar um lugar de (in)segurança na prática enunciativo-discursiva na FCB. O discurso literário da FCB demanda uma habilidade enunciativa de mobilizar espaços sociais a serviço de um novum que retire o co-enunciador de sua realidade latente, ao mesmo tempo impulsionando-o a questioná-la sob a ordem de um mundo diferente e semelhante ao real.

Por fim, estudar a relação entre os agentes essenciais para a comunicação literária e o discurso literário pode ser produtivo para a compreensão crítica das diversas formas de expressão e apreensão estética dos discursos literários brasileiros. Compreender que há uma pluralidade cultural que envolve a produção literária e que cada gênero literário demanda rotinas de interação, comunidades próprias e potências distintas favorecem a uma visão mais democrática e heterogênea da Literatura Brasileira. 


\section{Referências}

ABUSÕES. (2020). Dossiê: o boom da ficção científica. Revista Abusões. Vol. 11. Ano 6. e-ISSN: 2525-4022.

BERNARDO, Gustavo. O livro da metaficção. Rio de Janeiro: Tinta Negra Bazar Editorial. 2010.

BRAS, Luiz. Convite ao mainstream. Jornal Rascunho. Fev, 2012.

CAUSO, Roberto de Sousa. A editora Seoman e a ficção científica. In: Zanzalá: Revista brasileira de estudos de ficção científica. v.4. n.1, 2019. e-ISSN: 2236-8191.

DUARTE, Pedro. Gastaria tudo com pizza. São Paulo: Pipoca \& Nanquim, 2019.

FARIA, Zênia. A metaficção revisitada: uma introdução. Revista Signótica. vol. 24. n. 1, 2012. e-ISSN: 2316-3690.

HUTCHEON, Linda. Narcissistic Narrative: the metafictional paradox. New York: Methuen, 1984.

OLIVEIRA, Nelson de. Fractais Tropicais. São Paulo: SESI-SP, 2018. p. 70-79.

MAINGUENEAU, Dominique. O discurso literário. São Paulo: Contexto, 2006.

MAINGUENEAU, Dominique Textualidades diversas. Disponível em: https://www.youtube.com/watch?v=hR3J8o-zAeI. Último acesso em: jul. 2020.

MATANGRANO, Bruno; TAVARES, Enéias. Fantástico brasileiro: o insólito literário do romantismo ao fanatismo. Curitiba: Arte \& Letra, 2018.

NAVAS, Diana. Narcisismo discursivo e metaficção: Antonio Lobo Antunes e a revolução do romance. São Paulo: Scortecci, 2009.

NERDOLOGIA. Viagem no tempo. Disponível em: https://www. youtube.com/watch? $\mathrm{v}=\mathrm{Zd} 3 \mathrm{jWFpw} 3 \mathrm{NE}$. Último acesso em: jul. 2020. 
NO OLHAR DO SATÉLITE. Dica de livro: Gastaria tudo com pizza, de Pedro Duarte. Disponível em: https://noolhardosatelite.wordpress.com/2019/10/15/gastaria-tudo-com-pizza-pedro-duarte/. Último acesso em: jun. 2020.

NIETZSCHE, Friedrich. Obras incompletas. Seleção de textos: Gérard Lebrun. Trad. Rubens Torres Filho. São Paulo: Nova Cultura, 1999.

PIPOCA \& NANQUIM. Gastaria tudo com pizza. Disponível em: https://pipocaenanquim.com.br/produto/gastaria-tudo-com-pizza/. Último acesso jun. 2020.

ROBERTS, Adam. A verdadeira história da ficção científica: do preconceito à conquista das massas. Mário Molina (Trad.). São Paulo: Seoman, 2018. 